\title{
PENGARUH FASILITAS DAN PELAYANAN TERHADAP KEPUASAN PELANGGAN PADA PT MAFATI INOVASI TECHNOLOGY PONDOK CABE - TANGERANG SELATAN
}

\author{
Wahyu Nurul Faroh ${ }^{1)}$ Nurul Zahri' ${ }^{2)}$ \\ 1) dosen universitas pamulang, email : wahyunurulfaroh@gmail.com \\ ${ }^{2)}$ mahasiwa universitas pamulang.
}

\section{ARTICLES}

INFORMATION

ABSTRACT

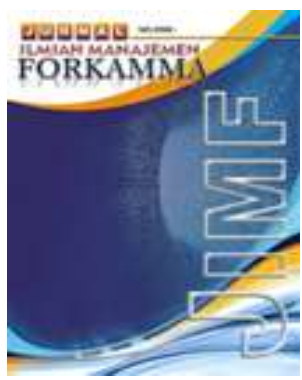

JURNAL ILMIAH MANAJEMEN FORKAMMA

Vol.2, No.3, Juli 2019

Halaman : $26-35$

(c) LPPM \& FORKAMMA

Prodi Magister Manajemen UNVERSITAS PAMULANG

ISSN (online) : 2599-171X

ISSN (print) : :2598-9545

Keyword:

Fasilitas, Pelayanan, Kepuasan Pelanggan.

JEL. classification :

C33, G20, G23, N65

Contact Author :

PRODI
MAGISTER MANAJEMEN \&
FORKAMMA UNPAM
JL.Surya Kencana No.1 Pamulang
Tangerang Selatan - Banten
Telp. (021) 7412566, Fax (021) 7412491
Email :
jurnalforkamma.unpam@gmail.com

Tujuan peneliian ini adalah untuk mengetahui pengaruh Fasilitas, Pelayanan terhadap Kepuasan Pelanggan baik secara parsial maupun simultan (Studi Kasus pada PT Mafati Inovasi Technology Pondok Cabe)

Teknik analisi yang digunakan adalah uji instrumen, uji korelasi ganda, uji asumsi klasik, analisis regresi berganda, pengujian hipotesis, dan koefisien determinasi dengan taraf signifikan 5\% menggunakan program SPSS for Windows Version 22.

Berdasarkan hasil penelitian ini yang pertama: menunjukan bahwa variabel Fasilitas dan Pelayanan memiliki pengaruh positif terhadap Kepuasan Pelanggan, Berdasarkan hasil uji simultan (uji F) sebesar 14,617 > Ftabel $(3,103)$ membuktikan bahwa variabel Fasilitas dan Iklan secara bersama-sama memilikik pengaruh posistif dan signifikan terhadap Kepuasan Pelanggan.

This research is intended to describe the influence of the Facilities, Services on Customer Satisfaction of Caltex Lubricants (Case Study at PT Mafati Pondok Cabe Technology Innovation). Techniques to advocate data and use questionnaires. The analysis technique used is the test instrument, multiple trials, classic assumption tests, multiple regression analysis, hypothesis testing, and coefficient of determination with a significant level of $5 \%$ using the SPSS program for Windows Version 22. Research results concluded there is a significant positive effect between Facilities and Services variables on customer satisfaction based on the results of simultaneous tests (test $F$ ) of 14,617> Ftable $(3,103)$ 


\section{A. Pendahuluan}

1. Latar Belakang Masalah.

PT Mafati Inovasi Technology didirikan pada tahun 2009 di jakarta yang merupakan anak dari perusahaan Pt Mafati Group yang bergerak dalam bidang minyak pelumas oli, grease, dan solar HSD import maupun lokal untuk pemakaian marine automotif dan saat ini juga telah memiliki anak perusahaan sebanyak dua belas.

Pada PT Mafati Inovasi Technology, perusahaan tersebut saat ini bergerak dalam bidang supplier berbagai macam produk pelumas pertamina salah satunya pelumas bermerek Caltex. Pelumas memiliki fungsi lain yang tak kalah penting, yakni antara lain sebagai; Pendingin, Pelindung dari Karat, Pembersih dan Penutup Celah pada Dinding Mesin.

Berikut ini merupakan data penjualan PT Mafati Inovasi Technology tahun 2016, sebagai berikut:

Tabel 1: Data Penjualan

\begin{tabular}{|c|c|c|}
\hline NO & Bulan & Penjualan \\
\hline 1 & Januari & Rp.331.123.374 \\
\hline 2 & Februari & Rp.280.133.598 \\
\hline 3 & Maret & Rp.315.124.096 \\
\hline 4 & April & Rp.299.576.806 \\
\hline 5 & Mei & Rp.315.017.022 \\
\hline 6 & Juni & Rp.533.358.030 \\
\hline 7 & Juli & Rp.443.563.236 \\
\hline 8 & Agustus & Rp.278.305.186 \\
\hline 9 & September & Rp.289.984.060 \\
\hline 10 & Oktober & Rp.378.368.182 \\
\hline 11 & November & Rp.4.008.033.295 \\
\hline 12 & Desember & TOTAL \\
\hline
\end{tabular}

Sumber : PT. Mafati Inovasi Technology, Maret - Juni 2017

Berdasarkan data penjualan di atas, penjualan perusahaan mengalami kenaikan dan penurunan tidak stabil. Terdapat masalah yang bisa memicu daya minat pelanggan untuk berkunjung kembali, masalah tersebut ialah pada fasilitas dan sarana di tempat penjualan produk tersebut. Kurangnya fasilitas dan sarana pada tempat ini akan membuat pelanggan merasa tidak betah dan pindah 
ketempat lain. Selain fasilitas dan sarana, pelayanan pada perusahaan dalam menjual produk kurang memberikan kepuasan kepada pelanggan, kendalanya pada kurangnya informasi, daya tanggap dan kehandalan karyawan dalam menangani keluhan konsumen. Untuk itu supaya menarik pelanggan agar datang kembali dan merasa puas dengan pelayanan yang diberikan pada perusahaan, fasilitas dan sarana serta pelayanan harus ditingkatkan untuk memberikan kepuasan terhadap pelanggan.

Sehingga penulis perlu melakukan penelitian dengan judul " Pengaruh Fasilitas Dan Pelayanan Terhadap Kepuasan Pelanggan Pada PT Mafati Inovasi Technology Pondok Cabe - Tangerang Selatan".

\section{Rumusan Masalah.}

a. Bagaimana pengaruh fasilitas terhadap kepuasan pelanggan pada PT Mafati Inovasi Technology?

b. Bagaimana pengaruh pelayanan terhadap kepuasan pelanggan pada PT Mafati Inovasi Technology?

c. Bagaimana pengaruh fasilitas dan pelayanan terhadap kepuasan pelanggan pada PT Mafati Inovasi Technology?

\section{Tujuan Penelitian.}

a. Mengetahui pengaruh fasilitas terhadap kepuasan pelanggan pada PT Mafati Inovasi Technology.

b. Mengethui pengaruh pelayanan terhadap kepuasan pelanggan pada PT Mafati Inovasi Technology

c. Menganalisis pengaruh fasilitas dan pelayanan terhadap kepuasan pelanggan pada PT Mafati Inovasi Technology.

\section{B. Kajian Teori}

\section{Fasilitas}

Menurut Prof. Dr. Veithzal Rivai dalam buku Manajemen Sumber Daya Manusia untuk Perusahaan Dari Teori ke Praktik (2008 : 234), pemberian fasilitas kerja pada pegawai termasuk di dalam pemberian kompensasi. Dikatakan dermikian, kompensasi mencakup tiga hal, yaitu : uang kontan, material dan fasilitas. Pemberian fasilitas ini juga balas jasa tambahan (fringe benefit) yang diberikan pada pegawai.

\section{Pelayanan}

Aktivitas, manfaat maupun kepuasan merupakan bentuk pelayanan yang pada dasarnya tidak berwujud. Hal ini diungkapkan Gronroos yang dikuitip oleh Tjiptono (2011:17) menyatakan bahwa pelayanan merupakan proses yang terdiri dari atas serangkaian aktivitas intangible (tidak berwujud) yang biasanya (namun tidak harus selalu) terjadi pada interaksi antara konsumen dengan karyawan jasa, sumber daya fisik, barang, atau sistem penyedia jasa yang disediakan sebagai solusi atas masalah konsumen. Dari definisi ini, dapat dikatakan bahwa pelayanan merupakan aktifitas yang diberikan kepada konsumen dan pada dasarnya tidak berwujud, disediakan sebagai solusi atas masalah konsumen. 


\section{Kinerja}

Satisfaction atau kepuasan menurut Irawan (2009:2) adalah kata dari bahasa latin yaitu satis yang berarti enough atau cukup dan farece yang berarti to do atau melakukan. Produk atau jasa yang bisa memuaskan adalah produk atau jasa yang sanggup memberikan sesuatu yang dicari konsumen sampai pada tingkat cukup. Kepuasan merupakan hasil dari penilaian konsumen bahwa produk atau pelayanan telah memberikan tingkat kenikmatan dimana tingkat pemenuhan ini bisa lebih atau kurang.

\section{Kerangka Berpikir.}

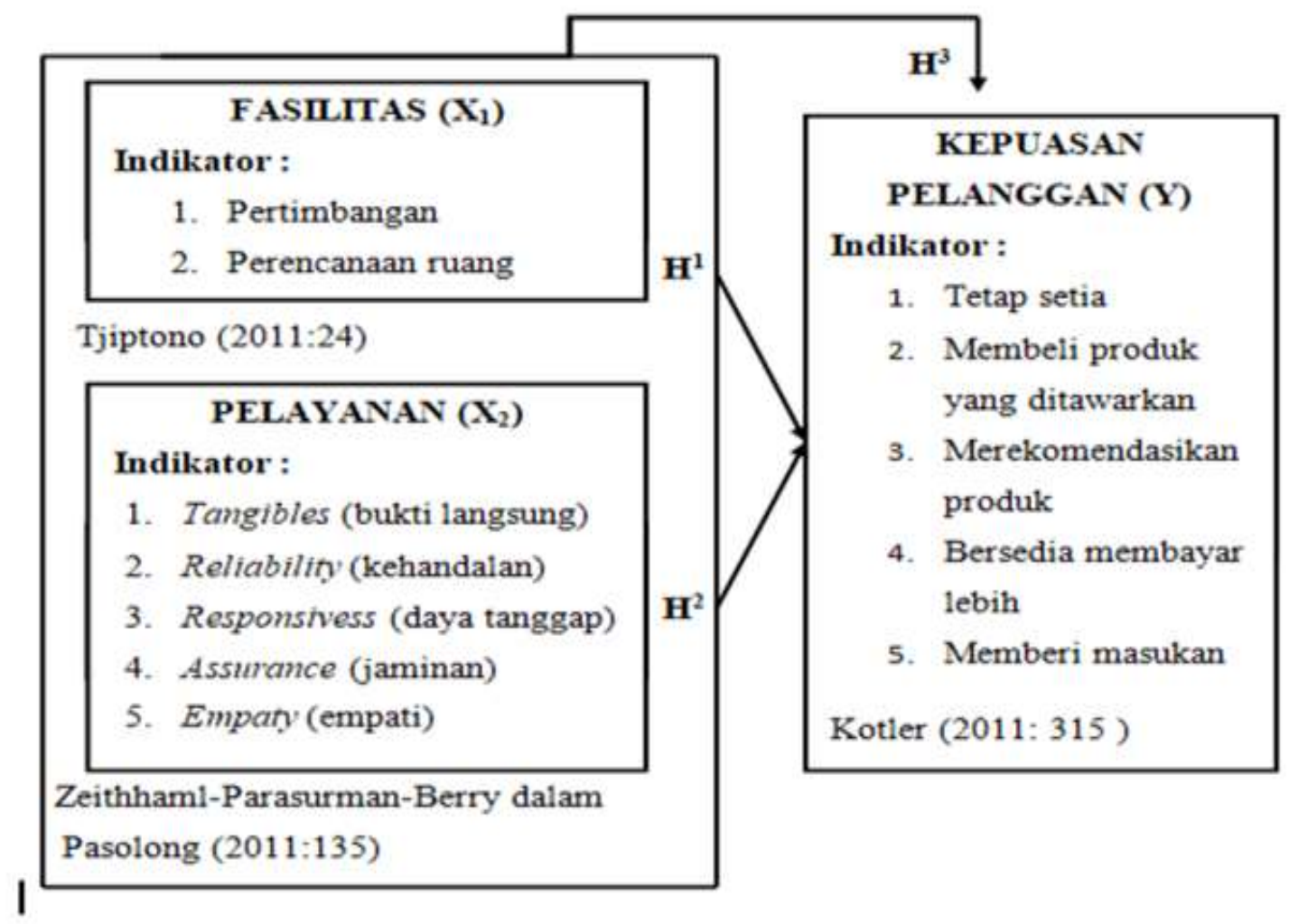

Gambar 1. Kerangka Berpikir

\section{Metodologi Penelitian}

\section{Obyek Penelitian.}

PT Mafati Inovasi Technology, Pondok Cabe, Tangerang Selatan, Provinsi Banten.

\section{Populasi dan Sampel.}

\section{a. Populasi}

Menurut Sugiyono (2016) menyampaikan bahwa "Populasi adalah jumlah wilayah generalisasi yang terdiri atas obyek atau subyek yang mempunyai kualitas dan karakteristik yang ditetapkan oleh perusahaan dan 
kemudian ditarik kesimpulannya". Dalam penelitian ini populasinya adalah Konsumen pelumas Caltex

b. Sampel

Menurut Sugiyono (2016) berpendapat "Sampel merupakan jumlah dan karakteristik yang dimiliki oleh populasi tersebut". Selanjutnya Sugiyono (2016) menjelaskan bahwa "Sampling jenuh merupakan teknik penentuan sampel apabila semua anggota populasi digunakan sebagai sampel". Dalam penelitian ini sampel yang digunakan 95 responden .

\section{Teknik Penentuan Data.}

Teknik penentuan data dalam penelitian ini menggunakan data primer dan data sekunder sesuai dengan data yang peneliti perlukan.

\section{Metode Pengumpulan Data.}

Menurut Sugiyono (2016) berpendapat bahwa "Metode pengumpulan data merupakan cara ilmiah dalam mengumpulkan data yang valid dengan tujuan dapat dibuktikan, dikembangkan suatu pengetahuan sehingga dapat digunakan untuk memecahkan masalah". Dalam penelitian ini menggunakan kuisioner.

\section{Metode Analisis Data.}

Metode analisis data dengan menggunakan Uji Instrumen, Uji Klasik, Uji Regresi Linear Berganda, dan Uji Hipotesis t dan $f$

\section{Hasil Penelitian dan Pembahasan}

\section{a. Uji Validitas}

Tabel. 2: Hasil uji validitas

\begin{tabular}{|c|c|c|c|c|}
\hline \multicolumn{5}{|c|}{ Hasil Uji Validitas Fasilitas } \\
\hline No & Pernyataan & $\begin{array}{c}\text { Nilai r } \\
\text { hitung }\end{array}$ & Nilai r tabel & Keterangan \\
\hline 1 & Pernyataan 1 & 0,452 & 0.169 & VALID \\
\hline 2 & Pernyataan 2 & 0,536 & 0.169 & VALID \\
\hline 3 & Pernyataan 3 & 0,527 & 0.169 & VALID \\
\hline 4 & Pernyataan 4 & 0,500 & 0.169 & VALID \\
\hline 5 & Pernyataan 5 & 0,450 & 0.169 & VALID \\
\hline 6 & Pernyataan 6 & 0,608 & 0.169 & VALID \\
\hline 7 & Pernyataan 7 & 0,570 & 0.169 & VALID \\
\hline 8 & Pernyataan 8 & 0,519 & 0.169 & VALID \\
\hline 9 & Pernyataan 9 & 0,316 & 0.169 & VALID \\
\hline 10 & Pernyataan 10 & 0,438 & 0.169 & VALID \\
\hline \multicolumn{7}{|c|}{ Hasil Uji Validitas Pelayanan } & VALID \\
\hline 1 & Pernyataan 1 & 0,546 & 0.169 & VALID \\
\hline 2 & Pernyataan 2 & 0,342 & 0.169 & VALID \\
\hline 3 & Pernyataan 3 & 0,551 & 0.169 & VALID \\
\hline 4 & Pernyataan 4 & 0,519 & 0.169 & VALID \\
\hline 5 & Pernyataan 5 & 0,479 & 0.169 & VALID \\
\hline 6 & Pernyataan 6 & 0,533 & 0.169 & \\
\hline
\end{tabular}




\begin{tabular}{|c|c|c|c|c|}
7 & Pernyataan 7 & 0,555 & 0.169 & VALID \\
\hline 8 & Pernyataan 8 & 0,413 & 0.169 & VALID \\
\hline 9 & Pernyataan 9 & 0,589 & 0.169 & VALID \\
\hline 10 & Pernyataan 10 & 0,514 & 0.169 & VALID \\
\hline \multicolumn{5}{|c|}{ Hasil Uji Validitas Kepuasan Pelanggan } \\
\hline 1 & Pernyataan 1 & 0,529 & 0.169 & VALID \\
\hline 2 & Pernyataan 2 & 0,587 & 0.169 & VALID \\
\hline 3 & Pernyataan 3 & 0,347 & 0.169 & VALID \\
\hline 4 & Pernyataan 4 & 0,549 & 0.169 & VALID \\
\hline 5 & Pernyataan 5 & 0,529 & 0.169 & VALID \\
\hline 6 & Pernyataan 6 & 0,609 & 0.169 & VALID \\
\hline 7 & Pernyataan 7 & 0,505 & 0.169 & VALID \\
\hline 8 & Pernyataan 8 & 0,509 & 0.169 & VALID \\
\hline 9 & Pernyataan 9 & 0,285 & 0.169 & VALID \\
\hline 10 & Pernyataan 10 & 0,504 & 0.169 & VALID \\
\hline
\end{tabular}

Sumber : Hasil Pengolahan Data, 2017

Hasil perhitungan uji validitas sebagaimana tabel 4diatas, menunjukan bahwa semua nilai rhitung lebih besar dari nilai rtabel (0.169) Sugiyono (2013:182). Oleh karena itu, dapat disimpulkan bahwa item dalam angket penelitian ini valid sehingga dapat digunakan sebagai instrumen penelitian

\section{b. Uji Reliabilitas}

Tabel 3: Hasil Uji Reliabilitas

\begin{tabular}{|c|l|c|c|c|}
\hline No & \multicolumn{1}{|c|}{ Keterangan } & $\begin{array}{c}\text { Cronbach's } \\
\text { Alpha }\end{array}$ & Nilai $\boldsymbol{r}$ tabel & Keterangan \\
\hline 1 & Fasilitas & 0,651 & 0,6 & RELIABEL \\
\hline 2 & Pelayanan & 0,675 & 0,6 & RELIABEL \\
\hline 3 & Kepuasan Pelanggan & 0,656 & 0,6 & RELIABEL \\
\hline
\end{tabular}

Hasil uji reliabilitas diperoleh nilai alpha semua variabel lebih besar dari nilai 0,60. Menurut Sugiyono (2013:184) dimana semua nilai Cronbach's Alpha ( $r$ alpha) yang dihasilkan lebih besar dari 0,60 dan dinyatakan semua data reliabel, Oleh karena itu, dapat disimpulkan bahwa semua angket dalam penelitian ini reliabel atau konsisten, sehingga dapat digunakan sebagai instrumen penelitian.

\section{c. Regresi Linear Berganda}

Tabel 4: Hasil Uji Regresi Linear Berganda

Berdasarkan tabel di atas diperoleh persamaan regresi linear berganda sebagai berikut:

$Y=16,209+0,425 X 1+0,160 X 2+e$

a. Konstanta (a) sebesar 16,209 menyatakan bahwa tanpa variabel Fasilitas, dan Pelayanan besarnya nilai Kepuasan Pelanggan tetap terbentuk sebesar 16,209. 
b. Variabel Fasilitas (X1) berpengaruh postif terhadap Kepuasan Pelanggan $(Y)$ dengan nilai koefisiensi sebesar 0,425 , yang artinya jika variabel Fasilitas (X1) meningkat satu satuan dengan asumsi variabel Pelayanan (X2) tetap, maka Kepuasan Pelanggan (Y) akan meningkat sebesar 0,425 , sehingga besar nya pengaruh Fasilitas terhadap Kepuasan Pelanggan sebesar 42,5\%.

d. Variabel Pelayanan (X2) berpengaruh positif terhadap Kepuasan Pelanggan ( $Y$ ) dengan nilai koefisien sebesar 0,160 yang artinya jika variabel pelayanan (X2) meningkat satu satuan dengan asumsi variabel Fasilitas (X1) tetap, maka Kepuasan Pelanggan (Y) akan meningkat sebesar 0,160. Sehingga besar nya pengaruh Fasilitas terhadap Kepuasan Pelanggan sebesar $16,0 \%$.

\section{e. Uji Hipotesis}

\section{a. Uji Parsial (Uji t)}

Coefficients $^{\mathrm{a}}$

\begin{tabular}{|ll|r|r|r|r|r|}
\hline \multirow{2}{*}{ Model } & \multicolumn{2}{|c|}{ Unstandardized Coefficients } & \multicolumn{2}{c|}{$\begin{array}{c}\text { Standardized } \\
\text { Coefficients }\end{array}$} & \multirow{2}{*}{} \\
\cline { 3 - 4 } & \multicolumn{1}{|c|}{$\mathrm{B}$} & \multicolumn{1}{|c|}{ Std. Error } & \multicolumn{1}{c|}{ Beta } & \multicolumn{1}{c|}{ Sig. } \\
\hline 1 & (Constant) & 16,209 & 4,602 & & 3,522 &, 001 \\
& Fasilitas &, 425 &, 107 &, 404 & 3,958 &, 000 \\
& Pelayanan &, 160 &, 109 &, 150 & 1,469 &, 145 \\
\hline
\end{tabular}

a. Dependent Variable: Kepuasan Pelanggan

Dari tabel 4.11 diatas dapat dilihat bahwa variabel Pelayanan diperoleh signifikansi t lebih besar dari 0,145 $(0,145>0,05)$ dan t hitung 1,469< t tabe Isebesar 1,986 $(1,469<1,986)$ atau berarti Ha2 diterima dan $\mathrm{H} 02$ ditolak, hal ini menunjukan bahwa varabel terdapat Terdapat Pengaruh Positif Dan Signifikan Antara Pelayanan Terhdap Kepuasan Pelanggan Pada PT Mafati Inovasi Technology.

\section{b. Uji Simultan (uji F)}

ANOVA $^{\mathrm{a}}$

\begin{tabular}{|rl|r|r|r|r|r|}
\hline Model & & \multicolumn{1}{c|}{$\begin{array}{c}\text { Sum of } \\
\text { Squares }\end{array}$} & df & Mean Square & \multicolumn{1}{c|}{ F } & Sig. \\
\hline 1 & Regression & 276,571 & 2 & 138,285 & 14,617 &, $000^{\mathrm{b}}$ \\
& Residual & 870,376 & 92 & 9,461 & & \\
& Total & 1146,947 & 94 & & & \\
\hline
\end{tabular}

a. Dependent Variable: Kepuasan Pelanggan

b. Predictors: (Constant), Pelayanan, Fasilitas

Dari hasil uji anova pada tabel diatas dapat diperoleh signifikansi $0,000<$ 0,05 dan F hitung 14,617 > F tabel 3,095 berarti H03 ditolak dan Ha1 diterima, maka Terdapat Pengaruh Positif Dan Signifikan Antara Fasilitas Dan Pelayanan Secara Bersama-Sama Terhadap Kepuasan Pelanggan Pada PT Mafati Inovasi Technology. 


\section{E Kesimpulan dan Saran}

\section{Kesimpulan}

Berdasarkan uraian pada bab-bab sebelumnya, dan dari hasil analisis serta pembahasan mengenai pengaruh fasilitas dan pelayanan terhadap kepuasan pelanggan, sebagai berikut :

1. Sesuai dengan perumusan masalah, maka besarnya pengaruh fasilitas terhadap kepuasan pelanggan yaitu sebesar 42,5 \%. Hal ini menunjukkan bahwa fasilitas yang baik akan meningkatkan kepuasan pelanggan. Dari pengujian hipotesis diperoleh $\mathrm{t}$ hitung $>\mathrm{t}$ tabel dan tsig $<0,05$ atau 3,958 $>$ 1,986 dan $0,00<0,05$, sehingga $\mathrm{H} 01$ ditolak dan Ha1 diterima hal ini menunjukan Terdapat Pengaruh Positif Dan Signifikan Antara Fasilitas Terhadap Kepuasan Pelanggan Pada PT Mafati Inovasi Technology.

2. Sesuai dengan perumusan masalah, maka besarnya pengaruh pelayanan terhadap kepuasan pelanggan yaitu sebesar $16,0 \%$. Hal ini menunjukkan bahwa pelayanan yang baik akan meningkatkan kepuasan pelanggan. Dari pengujian hipotesis diperoleh t hitung $>\mathrm{t}$ tabel dan tsig $<0,05$ atau 1,469 $>$ 1,986 dan 0,145 $<0,05$, sehingga H01 diterima dan Ha1 ditolak hal ini menunjukan Terdapat Pengaruh Positif Dan Signifikan Antara Pelayanan Terhadap Kepuasan Pelanggan Pada PT Mafati Inovasi Technology.

3. Sesuai dengan perumusan masalah, maka dilihat dari hasil dari nilai korelasi berganda besarnya pengaruh fasilitas (X1) dan pelayanan (X2) terhadap kepuasan pelanggan $(Y)$ sebesar 0,491, artinya fasilitas dan pelayanan memberikan kontribusi sebesar 49,1\%, tehadap kepuasan pelanggan $(Y)$ sedangkan Fasilitas (X1) dan Pelayanan (X2) berkontribusi terhadap Kepuasan Pelanggan $(Y)$ dengan persamaan regresi linear berganda $Y=16,209+0,425 X 1+0,160 X 2+e$, dan nilai koefisiensi determinasi sebesar $24,1 \%$ sedangkan sisanya sebesar $75,9 \%$ dipengaruhi oleh variabel lain. Dari pengujian hipotesis menggunakan uji statistik Fhitung 14,617 > Ftabel 3,103, hal tersebut juga diperkuat dengan probability $0,000<0,05$. Dengan demikian $\mathrm{HO}$ ditolak dan $\mathrm{Ha}$ diterima. Artinya terdapat pengaruh positif dan signifikan secara simultan antara fasilitas dan pelayanan terhadap kepuasan pelanggan Pada PT Mafati Inovasi Technology

\section{Saran-saran}

1. Fasilitas (X1) pihak perusahaan harus lebih meningkatkan kembali kualitas fasilitas agar lebih kreatif dan inovatif sehingga dapat lebih menarik perhatian pelanggan agar melakukan pembelian

2. Pelayanan (X2) pihak perusahaan harus lebih meningkatkan kualitas pelayanan agar pelanggan merasa puas.

3. Kepuasan Pelanggan ( $\mathrm{Y}$ ) pihak perusahaan sebaiknya lebih meningkatkan fasilitas seeta pelayanan di dalam perusahaan yang saat ini kurang memberikan kepuasan terhadap pelanggan. 


\section{Daftar Pustaka}

Agus Sulastiyono. 2011. Manajemen Penyelenggaraan Hotel: Manajemen Hotel. Bandung: Alfabeta.

Bilson, Simamora. 2011. Memenangkan Pasar dengan Pemasaran Efektif dan Profitabel. Jakarta : PT. Gramedia Pustaka Utama.

Ghozali, Imam. 2013. Aplikasi Analisi Multivariet Dengan Program SPSS. Edisi Ketujuh. Semarang : Badan Penerbit Universitas Diponegoro.

Greenberg, P. 2010. Costumer Relationship Management at The Speed Of Light: Fourth Edition, McGraw-Hill.

Hasibuan, Malayu S.P. 2012. Manajemen Sumber Daya Manusia. Jakarta : PT Bumi Aksara.

Handi Irawan, 2009. 10 Prinsip Kepuasan Pelanggan, Cetakan Ketujuh, Jakarta : Elex Media Komputindo.

Hasibuan, Malayu S.P 2009. Manajemen: Dasar, Pengertian, dan Masalah Edisi Revisi. Jakarta : Bumi Aksara.

Handoko, T. Hani. 2009. Manajemen. Cetakan Duapuluh, Yogyakarta : Penerbit BPEE.

Kotler dan Keller. 2012. Marketing Management Edisi 14. Global Edition. Person Prentice Hall.

Kotler, Philip dan Kevin Lane Keller. 2012. Manajemen Pemasaran jilid 2.

Kotler, Philip dan Kevin Lane Keller. 2012. Marketing Management Edisi 14. New Jersey : Person Prentice Hall.

Kotler, Philip dan Gary Amstrong. 2009. Prinsip-Prinsip Pemasaran Edisi 12. Jilid 2. Jakarta : Erlangga.

Moenir, A.S. 2010. Manajemen Pelayanan Umum Di Indonesia. Jakarta : Bumi Aksara.

Nawawi, Ismail. 2009. Public Policy, Analisis, Strategi Advokasi Teori dan Praktek. Surabaya: PMN.

Sfroni, Ladzi. 2012. Manajemen dan Reformasi Pelayanan Publik dalam Konteks Birokrasi Indonesia. Surabaya : Aditya Media Publishing.

Salam, Darma Setyawan. 2007. Manajemen Pemerintahan Indonesia. Jakarta : Djambatan.

Sunyoto, D. 2012. Manajemen Sumber Daya Manusia. Yogyakarta : CAPS

Sugiyono. 2010. Metode Kuantitatif Kualitatif dan RAD : Penerbit CV Alfabeta. Bandung.

Sugiyono. 2014. Metode Kuantitatif Kualitatif dan Kombinasi (Mixed Methods). Bandung : Alfabeta.

Sugiyono. 2012. Data Kuantitatif. Data kuantitatif adalah metode penelitian yang berdasarkan pada filsafat positivisme. Bandung : Alfabeta 
Tjiptono, Fandy. 2014. Pemasaran Jasa. Jakarta : Gramedia Cawang.

Tjiptono, Fandy. 2011. Pemasaran Jasa, Banyumedia, Malang.

Wiliam J, \& Stanton. 2009. Prinsip Pemasaran. Jilid I. Jakarta. Erlangga. 